\title{
In-situ study of growth of carbon nanotube forests on conductive $\mathrm{CoSi}_{2}$ support
}

\author{
B. C. Bayer ${ }^{1}$, C. Zhang ${ }^{1}$, R. Blume ${ }^{2, \#}$, F. Yan $^{1}$, M. Fouquet ${ }^{1}$, C. T. Wirth ${ }^{1}$, R. S. Weatherup ${ }^{1}$, L. Lin ${ }^{1}$, \\ C. Baehtz ${ }^{3}$, R. A. Oliver ${ }^{4}$, A. Knop-Gericke ${ }^{2}$, R. Schlögl ${ }^{2}$, S. Hofmann ${ }^{1}$, J. Robertson ${ }^{1, *}$
}

\author{
${ }^{1}$ Department of Engineering, University of Cambridge, Cambridge, CB3 OFA, UK \\ ${ }^{2}$ Fritz-Haber-Institut der Max-Planck-Gesellschaft, D-14195 Berlin-Dahlem, Germany \\ ${ }^{3}$ Institute of Ion Beam Physics and Materials Research, Helmholtz-Zentrum Dresden-Rossendorf, D-01314 Dresden, \\ Germany \\ ${ }^{4}$ Department of Materials Science and Metallurgy, University of Cambridge, Cambridge, CB2 3QZ, UK
}

* Corresponding author: e-mail jr214@ hermes.cam.ac.uk,

Received 26 January 2011; accepted 13 April 2011; published online 9 June 2011

\begin{abstract}
The growth of high density vertically aligned carbon nanotube forests on conductive $\mathrm{CoSi}_{2}$ substrate layers is characterised by in-situ $\mathrm{X}$-ray photoemission spectroscopy and X-ray diffraction. We use in-situ silicidation to transform as loaded, low conductivity CoSi supports to highly conductive $\mathrm{CoSi}_{2}$ during nanotube growth. These $\mathrm{CoSi}_{2}$ films are found to be stable against oxidation and carbide formation during growth and act as an excellent metallic support for growth of aligned nanotubes, resembling the growth on the insulating $\mathrm{Fe} / \mathrm{Al}_{2} \mathrm{O}_{3}$ benchmark system. The good catalytic activity is attributed to interfacial reactions of the Fe catalyst particles with the underlying CoSi ${ }_{2}$ support. We obtain ohmic conduction from the support layer to the CNT forest.
\end{abstract}

Keywords: carbon nanotubes, catalysis, catalysts, chemical vapour deposition, cobalt alloys, electrical conductivity, metal-insulator boundaries, metallic thin films, nanofabrication, ohmic contacts, oxidation, silicon alloys, X-ray diffraction, X-ray photoelectron spectra

\section{Introduction}

Carbon nanotubes (CNTs) are a promising material for use as interconnects between transistors in integrated circuits [1-3]. This is due to their very high current carrying capacity of $\sim 10^{9} \mathrm{~A} / \mathrm{cm}^{2}$, resistance to electromigration, and their ability to be grown in deep, high aspect ratio holes. These properties are a direct advantage over the presently used $\mathrm{Cu}$ when feature sizes are further scaled down in vertical interconnects (vias), which connect the various metallization levels in integrated circuits. This application requires the CNTs to be grown by chemical vapour deposition (CVD) in very high density vertically-aligned forests [4-11]. There has been great progress in growing such forests on insulating substrates such as $\mathrm{Al}_{2} \mathrm{O}_{3}$ or $\mathrm{SiO}_{2}$ [12-21]. However the growth of such forests of CNTs on conductive substrates is a more challenging process due to the much higher surface energy of metals than insulating oxides (Table 1). The higher surface energy inhibits the catalyst film from transforming itself into a series of nanoparticles [2226]. In addition, the metallic support must retain its conductivity/functionality during the CVD processes at elevated temperatures in the presence of reactive gases, but metals are often reactive themselves under such conditions [27]. This means that supports must possess both favourable surface energetics for high density nanoparticle formation and a chemical stability against carbide-formation (from carbon source gas) or oxidation (from residual oxygen or water).

Ta has been used by some groups as a metallic support, because it is a useful diffusion barrier material already used in microelectronics. Good CNT growth was achieved on this metal. However, detailed in-situ study of CNT 
Table 1: Surface energies of solid metals, metallic compounds and oxides, in $\mathrm{J} / \mathrm{m}^{2}$, from [26].

\begin{tabular}{|l|l|l|}
\hline & experiment & theory \\
\hline $\mathrm{Ni}$ & 2.08 & 2.01 \\
\hline $\mathrm{Co}$ & 2.22 & 2.77 \\
\hline $\mathrm{Fe}$ & $2.12,1.72$ & 2.22 \\
\hline $\mathrm{TiN}$ & & $1.6,1.40$ \\
\hline $\mathrm{CoSi}_{2}$ & $0.72-0.8$ & 1.65 \\
\hline $\mathrm{NiSi}_{2}$ & & 1.13 \\
\hline $\mathrm{SiO}_{2}$ & $0.043-0.11$ & \\
\hline $\mathrm{Al}_{2} \mathrm{O}_{3}$ & $0.06-0.1$ & $0-0.1$ \\
\hline $\mathrm{MgO}$ & 0.1 & \\
\hline
\end{tabular}

growth on Ta found that Ta could be easily oxidised by residual oxygen in the presence of some growth catalysts like $\mathrm{Fe}$, and that $\mathrm{Ta}$ also tended to form Ta carbide [27]. This suggests the use of metallic compounds. TiN and TaN are widely used in microelectronics and CNTs have been found to grow on these supports $[25,28]$. However, the nitride surfaces are easily oxidised [28,29]. This suggests silicides as an alternative due to their high stability. $\mathrm{CoSi}_{2}$ is a commonly used contact material in integrated circuit fabrication [30-37]. We recently found that $\mathrm{CoSi}_{2}$ is a promising candidate to combine favourable surface energetics and chemical stability [26].

In this paper, we evaluate Co-silicides further as supports for high density CNT growth by employing in-situ chemical and structural characterisation techniques to study the evolution of the silicide-catalyst-gas system during CNT forest growth. We correlate our findings with the electrical characterisation of silicide-supported CNT forests. To keep the thermal budget of the silicide films sufficiently low (to avoid e.g. film inversion or mixing [30-32]), we initially deposit the Fe catalyst onto not fully crystallized, low conductivity Co-monosilicide ( $\mathrm{CoSi}$ ) and then transform it to the high conductivity phase Co-disilicide $\left(\mathrm{CoSi}_{2}\right)$ in-situ during the CNT growth (Figure 1). Thereby we show that we promote growth of the CNTs onto a fresh, in-situ formed film microstructure and surface, hence limiting the effects of transporting the films in air during process steps.

\section{Experimental details}

The silicide films were prepared by the low pressure CVD of $\sim 200 \mathrm{~nm}$ poly-Si onto polished single crystalline $\mathrm{Si}$ (100) wafers, followed by sputter deposition of a $\sim 15 \mathrm{~nm}$ Co layer. This structure was capped by a TiN layer and annealed by rapid thermal annealing (RTA) at temperatures under $500^{\circ} \mathrm{C}$ for under $3 \mathrm{~min}$, followed by the removal of the TiN capping layer. The annealing led to interdiffusion of the Co and the $\mathrm{Si}$ and the formation of $\mathrm{CoSi}$ (see below). The TiN capping layer promotes the development of a smoother silicide surface. Usually a second, further annealing step is then employed to transform the CoSi into high conductivity $\mathrm{CoSi}_{2}$ [30-32]. We can avoid this second step as we transform $\mathrm{CoSi}$ into $\mathrm{CoSi}_{2}$ simultaneously with the CNT growth.

After transport of CoSi wafers in air, a $\sim 1 \mathrm{~nm} \mathrm{Fe}$ catalyst layer was deposited onto the samples by thermal evaporation. CNT growth and simultaneous silicide transformation was conducted in atmospheric, near-atmospheric or low pressure CVD conditions as summarised in Table 2. The structural evolution of samples was monitored during near-atmospheric CVD by in-situ X-ray diffractometry (XRD) and X-ray reflectivity (XRR) [27]. In-situ (grazing incidence) XRD and XRR was measured at ROBL/BM20, operated by the Helmholtz-Zentrum Dresden Rossendorf, at the European Synchrotron Radiation Facility (XRD scans plotted at $1.541 \AA$ ). The evolution of the surface chemistry of samples was monitored during low pressure CVD by in-situ X-ray photoelectron spectroscopy (XPS) $[38,39]$. In-situ XPS was measured at the ISISS end station of the FHI-MPG at BESSY II. For details of the in-situ XPS apparatus see ref. [40].

Post-growth analysis of samples was carried out by Scanning Electron Microscopy (SEM, FEI Philips XL30 sFEG) and Raman spectroscopy (Renishaw 1000, $514 \mathrm{~nm}$ excitation). Electrical measurements were carried out with a two terminal probe station (Cascade with Agilent Technologies B1500A semiconductor parameter analyser) as well as with a conductive tip IV-AFM setup (Veeco Dimension 3100 with Nanoscope $\mathrm{V}$ controller and Veeco Extended TUNA module with a Pt-Ir coated tip).

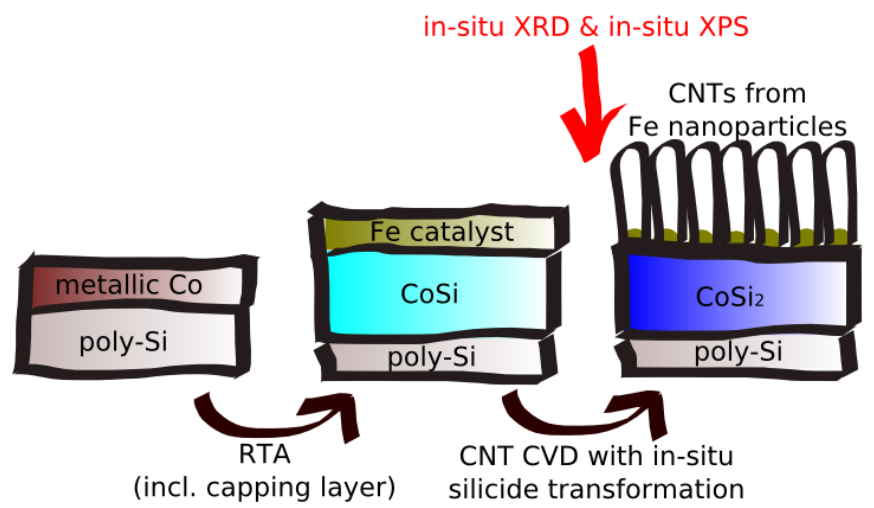

Figure 1: Schematic of in-situ silicidation from low conductivity CoSi to highly conductive $\mathrm{CoSi}_{2}$ during CNT growth. 
Table 2: Summary of CVD conditions. Low pressure and near-atmospheric pressure CVD were conducted in custom-built reaction chambers with heating stages (cold wall). Atmospheric pressure CVD was done in a custom-built quartz tube furnace (hot wall).

\begin{tabular}{|c|c|c|c|c|}
\hline & Ramp & Pre-treatment & Growth & In-situ characterisation \\
\hline Low pressure & $\begin{array}{l}\text { in } 0.1-0.5 \text { mbar } \mathrm{NH}_{3} \\
\text { at } \sim 300^{\circ} \mathrm{C} / \mathrm{min}\end{array}$ & $\begin{array}{l}\text { in } 0.1-0.5 \text { mbar } \mathrm{NH}_{3} \text { at } \\
\sim 650^{\circ} \mathrm{C} \text { for } 10-60 \mathrm{~min}\end{array}$ & $\begin{array}{l}\text { add } 10 \% \mathrm{C}_{2} \mathrm{H}_{2} \text { to pre-treatment } \\
\text { conditions for } 20-30 \mathrm{~min}\end{array}$ & In-situ XPS at BESSY II \\
\hline $\begin{array}{l}\text { Near-atmospheric } \\
\text { pressure }\end{array}$ & $\begin{array}{lr}\text { in } 150-250 & \text { mbar } \\
\text { Ar: } \mathrm{H}_{2} & \text { at } \\
\sim 100^{\circ} \mathrm{C} / \mathrm{min} & \end{array}$ & $\begin{array}{l}\text { in } 150-250 \mathrm{mbar} \mathrm{Ar}: \mathrm{H}_{2} \text { at } \\
\sim 650^{\circ} \mathrm{C} \text { for } 90 \mathrm{~min}\end{array}$ & $\begin{array}{l}\text { add } \sim 2 \% \quad \mathrm{C}_{2} \mathrm{H}_{2} \text { to pre-treatment } \\
\text { conditions for } 90 \mathrm{~min}\end{array}$ & $\begin{array}{l}\text { In-situ XRD and XRR at } \\
\text { ROBL/ESRF }\end{array}$ \\
\hline Atmospheric pressure & $\begin{array}{l}\text { in } 1000 \mathrm{mbar} \mathrm{Ar} \text { at } \\
20^{\circ} \mathrm{C} / \mathrm{min}\end{array}$ & $\begin{array}{l}\text { in } 1000 \text { mbar } \mathrm{Ar}: \mathrm{H}_{2} \text { at } \\
650^{\circ} \mathrm{C}-750^{\circ} \mathrm{C} \text { for } 3 \mathrm{~min}\end{array}$ & $\begin{array}{l}\text { add } 2 \% \quad \mathrm{C}_{2} \mathrm{H}_{2} \text { to pre-treatment } \\
\text { conditions for } 30 \mathrm{~min}\end{array}$ & - \\
\hline
\end{tabular}

\section{Results}

\subsection{Growth}

Multi-walled nanotube forests of tens of $\mu \mathrm{m}$ height are found to grow easily on the Co-silicide support under the atmospheric and low-pressure conditions listed in Table 2. This is confirmed by SEM (Figure 2) and Raman spectroscopy (not shown), consistent with our previous report [26]. The nanotube density is estimated at $\sim 10^{10} \mathrm{CNTs} / \mathrm{cm}^{2}$ from the SEM micrographs [41]. Near-atmospheric CVD conditions lead to somewhat lower density CNT growth with less alignment (not shown), but are interesting because they allow in-situ XRD.
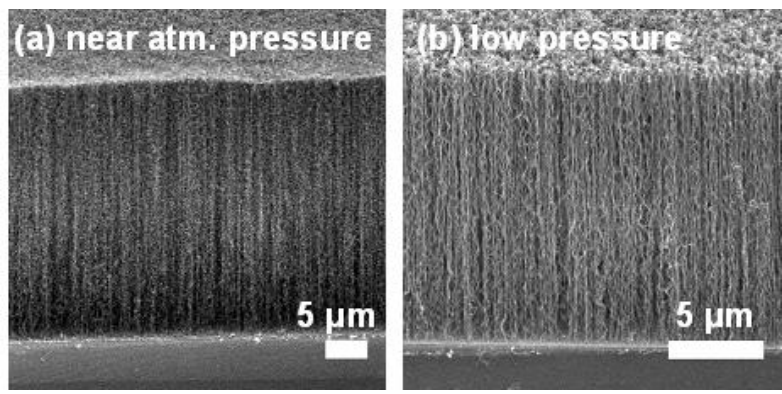

Figure 2: Typical CNT forest growth results with the CVD conditions from Table 2 (SEM micrographs at a tilt of $\sim 60^{\circ}$ ). In particular, (a) shows atmospheric pressure CVD at $650^{\circ} \mathrm{C}$. (b) shows low pressure CVD at $\sim 0.1$ mbar with $30 \mathrm{~min}$ pre-treatment and $30 \mathrm{~min}$ growth at $\sim 650^{\circ} \mathrm{C}[41]$.

\section{2. $X R D$}

Figure 3(a) shows that the structural evolution of the silicide during near-atmospheric pressure CVD, as measured by in-situ XRD (information depth $\sim 70 \mathrm{~nm}$, due to grazing incidence setup), is as expected from the process flow in Figure 1: The as-loaded silicide film shows reflections corresponding to poly-Si [42] and a small contribution of two reflections which can be assigned to $\mathrm{CoSi}$ [42]. The

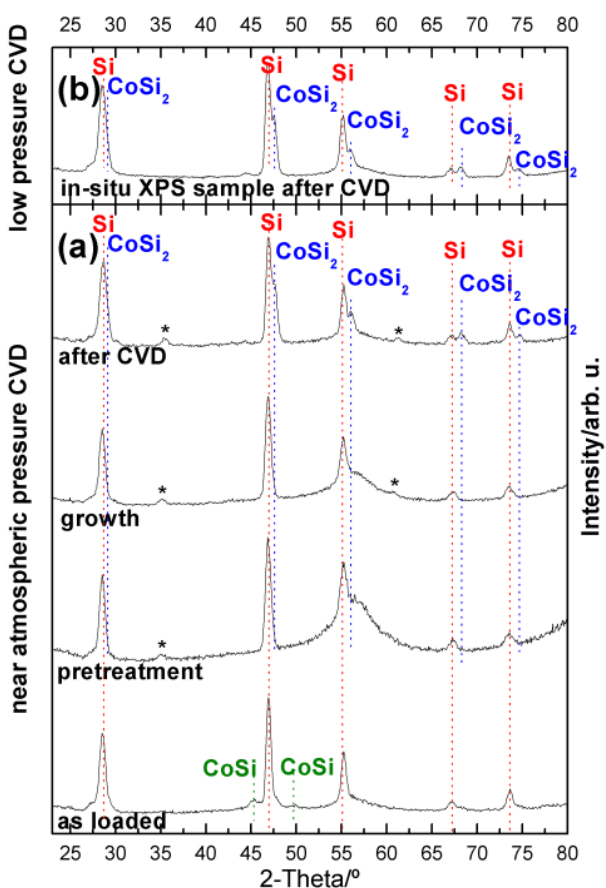

Figure 3: (a) Process-step resolved structural evolution of silicide supports during near-atmospheric pressure CVD as measured by in-situ XRD. CoSi in the as loaded samples is transformed into $\mathrm{CoSi}_{2}$ during the CNT CVD. * designates reflections which may be related to a minor Co-oxide/silicate contribution. (b) Ex-situ XRD scan of a sample after low pressure CVD conditions. (Diffraction patterns are plotted for $1.541 \AA \mathrm{X}$-ray wavelength.)

small magnitude of the CoSi signal is ascribed to low crystallinity of the monosilicide film after its formation by the low temperature RTA. The Fe is not visible in XRD due to its very small film thickness and a partial reflection overlap.

During pre-treatment in $\mathrm{H}_{2} / \mathrm{Ar}$ at $\sim 650^{\circ} \mathrm{C}$ we find that most poly-Si related reflections develop a shoulder to higher angles. We ascribe this to the formation of $\mathrm{CoSi}_{2}$. The reflections of the formed $\mathrm{CoSi}_{2}$ [42] become fully visi 


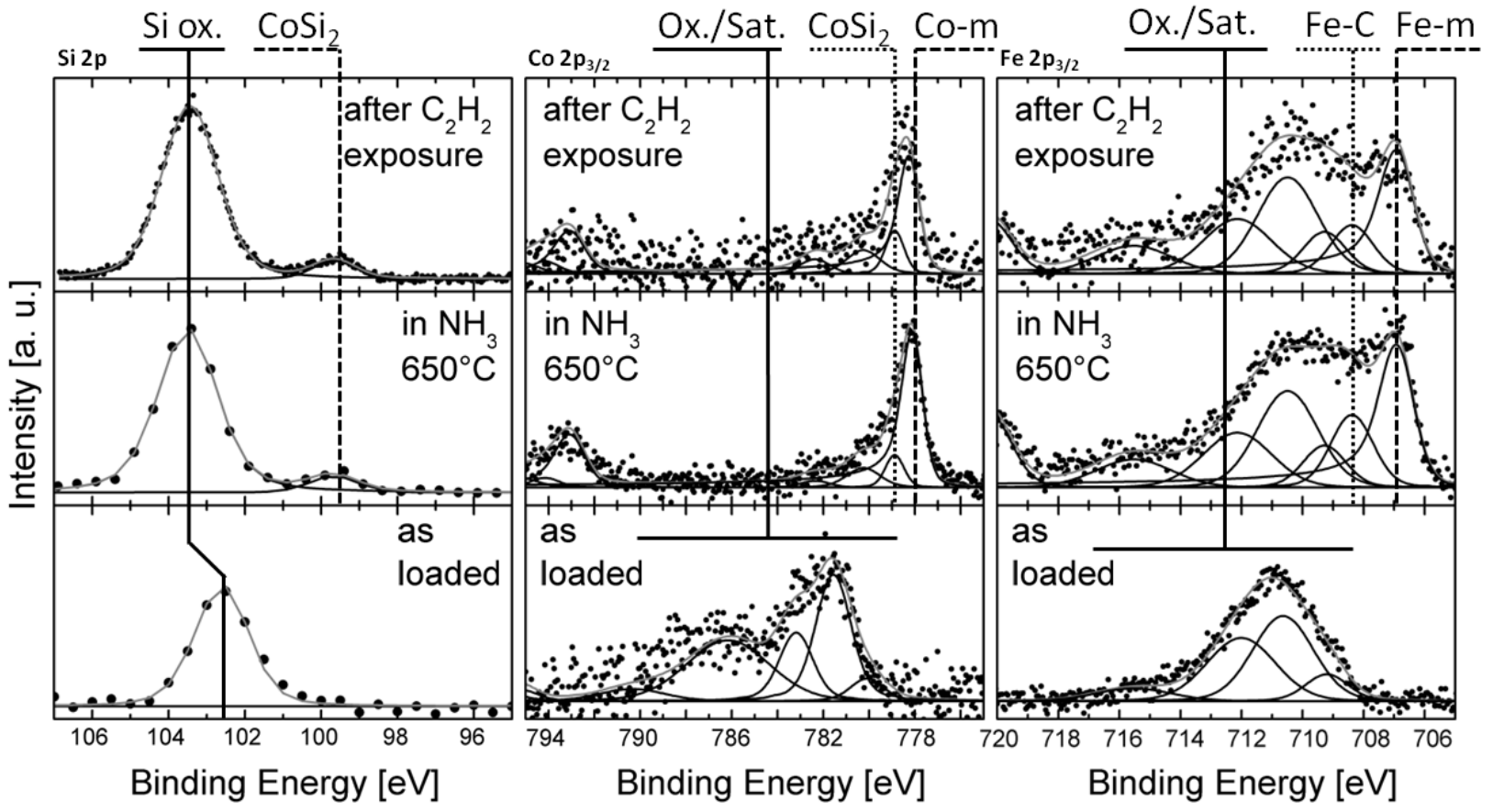

Figure 4: (from left to right) In-situ XPS spectra of the Si2p, Co 2 $\mathrm{p}_{3 / 2}$ and $\mathrm{Fe} 2 \mathrm{p}_{3 / 2}$ regions showing the evolution of the surface $\left(\mathrm{Fe}, \mathrm{Co} ; \mathrm{E}_{\mathrm{kin}}\left(\mathrm{e}^{-}\right)=\right.$ $150 \mathrm{eV})$ and near surface $\left(\mathrm{Si} ; \mathrm{E}_{\text {kin }}\left(\mathrm{e}^{-}\right)=1000 \mathrm{eV}\right)$ chemistry under low pressure CVD.

ble in the post-deposition scan with its higher signal/noise ratio. As the $\mathrm{CoSi}_{2}$ appears during $\mathrm{CVD}$ the $\mathrm{CoSi}$ reflections disappear, following the established silicidation model for Co-silicides of (poly-Si/Co $\rightarrow \mathrm{Co}_{2} \mathrm{Si} \rightarrow$ ) $\mathrm{CoSi} \rightarrow$ $\mathrm{CoSi}_{2}$ [30-32]. From additional XRR measurements (not shown) we estimate a silicide thickness of $\sim 20 \mathrm{~nm}$. In some samples, we find two additional low intensity reflections which remain ambiguous to assign. They may be related to Co-silicate or Co-oxide [42]. This is ascribed to the silicide or residual $\mathrm{Co}$ on the surface reacting with residual oxygen or water in the chamber. We note however that this contribution is small and limited to some near-atmospheric samples. For low pressure CVD, post-growth XRD scans show similarly the formation of $\mathrm{CoSi}_{2}$, but without any possible Co-oxide/-silicate contributions (Figure 3(b)). This is due to the cleaner environment in low pressure CVD (base pressure $\sim 10^{-6}$ mbar) compared to a greater oxygen or water contamination in the near-atmospheric pressure system.

Our XRD data confirms that we indeed form crystalline $\mathrm{CoSi}_{2}$ in-situ during the CVD process, consistent with our process flow. Notably, in none of our samples we find uncalled-for formation of carbides, other material interactions such as catalyst-support-alloying or complete transformation of the "bulk" of the film into an oxide, as occurred for the case of CNT growth on Ta under similar conditions [27].

\section{3. $X P S$}

We use surface sensitive (1-3 nm maximum information depth) in-situ XPS to measure the chemical state of the support, the Fe catalyst and the growing nanotubes during low pressure CVD, to complement the XRD measurements of the structural evolution of the "bulk" silicides. Figure 4 shows that the surface of the as-loaded monosilicide consists of oxidised Co $(779.9 \mathrm{eV}$ and $781.6 \mathrm{eV})$ and Si-oxide $(102.6 \mathrm{eV})$ [43-45]. This is expected, as the samples were transported in air between process steps and measurements and Co-silicide is known to form a thin native oxide when exposed to ambient conditions [30]. The Co-oxide might also stem from unreacted Co residues from the low temperature RTA silicidation. The Fe catalyst film is also completely oxidized, exhibiting a satellite structure in the XPS spectra which suggests that additionally $\mathrm{OH}$ groups are present $\left(\mathrm{Fe}^{2+}: 709.2 \mathrm{eV}, \mathrm{Fe}^{3+}: 710.6 \mathrm{eV}\right)[46,47]$.

During pretreatment (heating in $\mathrm{NH}_{3}$ ) the surface Co is almost completely reduced $(778.2 \mathrm{eV})$, while the Si stays oxidized [48]. The latter is also expected as it is known that metallic Co cannot reduce $\mathrm{SiO}_{2}$ during silicidation (unlike e.g. Ti [30]), nor is $\mathrm{SiO}_{2}$ affected by $\mathrm{NH}_{3}$ [39]. We find however, as in XRD, that $\mathrm{CoSi}_{2}$ is formed on the surface during the pretreatment (development of peaks at $778.9 \mathrm{eV}$ in Co2p and $299.7 \mathrm{eV}$ in Si2p, [49]), again in accordance with our process flow. This means that when we introduce $\mathrm{C}_{2} \mathrm{H}_{2}$ into the CVD chamber in the next step, CNTs are at least partially growing on a freshly formed $\mathrm{CoSi}_{2}$ surface, 
possibly where the native oxide is thinnest. We measure corresponding electrical characteristics below.

During annealing the Fe catalyst layer does split into nanoparticles [26] but we find that it is only partially reduced (reduction evidenced by the appearance of a component at $706.9 \mathrm{eV}$ ). This is in contrast to $\mathrm{Fe}$ during $\mathrm{NH}_{3}$ pretreatment on $\mathrm{SiO}_{2}$ where the $\mathrm{Fe}$ is fully reduced [38]. The silicide support seems to retain some of the $\mathrm{Fe}$ in its oxidized form. The formation of an interfacial $\mathrm{Fe}$ oxide layer was also found for Fe-catalysed CNT growth on $\mathrm{Al}_{2} \mathrm{O}_{3}$, which is the most successful support/catalyst combination for high density CNT growth on an insulator so far [38]. $\mathrm{On}_{2} \mathrm{O}_{3}$ the interfacial oxide layer pins down the $\mathrm{Fe}$, preventing the catalyst nanoparticles from excessive sintering and in turn allowing high density CNT growth to occur. We have shown previously by ex-situ AFM study that Co$\mathrm{Si}_{2}$ similarly seems to inhibit the sintering of $\mathrm{Fe}$ nanoparticles, which in turn allows the efficient growth of CNT forests [26]. Now, our XPS data suggests that the Fe nanoparticles become stabilized on the $\mathrm{CoSi}_{2}$ surface by an interfacial reaction, in a similar fashion as occurs for $\mathrm{Fe}$ on $\mathrm{Al}_{2} \mathrm{O}_{3}[38,50]$.

When we add $10 \% \mathrm{C}_{2} \mathrm{H}_{2}$ to the $\mathrm{NH}_{3}$, the XPS $\mathrm{C} 1 \mathrm{~s}$ spectra (not shown) evidence a rapid evolution of $\mathrm{sp}^{2}-$ and $\mathrm{sp}^{3}$-carbon related peaks, typical of CNT growth [38,39]. In fact, the growth rate of the obtained forests from standard low pressure CVD (Figure 2(b)) is too fast to allow the acquisition of high resolution XPS scans of the silicide during $\mathrm{C}_{2} \mathrm{H}_{2}$ exposure. After growth, the $10-40 \mu \mathrm{m}$ high CNT layers prevent the escape of photoelectrons from the silicide/CNT interface to the XPS detector, so no information about the post-CVD silicide surface can be gained through the forests. Therefore, to measure the chemical state of the interface during growth, we deliberately only pulse the $\mathrm{C}_{2} \mathrm{H}_{2}$, leading to a sparse growth of CNTs, but allowing us to probe the silicide surface. After $\mathrm{C}_{2} \mathrm{H}_{2}$ exposure, we find on the surface a mixture of metallic $\mathrm{Co}$ and $\mathrm{CoSi}_{2}$ plus unreduced $\mathrm{SiO}_{2}$, but no Co- or Si-carbides. The state of the $\mathrm{Fe}$ did not significantly change with $\mathrm{C}_{2} \mathrm{H}_{2}$ exposure. As noted above, we cross-checked the XPS data with post-growth XRD of the same samples (Figure 3(b)), where we find only poly-Si and $\mathrm{CoSi}_{2}$ in the films. This implies that the Si-oxides seen in XPS are only thin surface oxides, which do not extend into the bulk of the film. This is also corroborated by the electrical characterization, below.

XPS shows that the silicide surface consists of metallic $\mathrm{Co}$ and $\mathrm{Co}$-silicide after the reducing pre-treatment stage. The metallic Co could be due to either unreacted Co residues or to Co originating from the break-up of the silicide due to the formation of the thin native oxide layer. Morphologically, the surface is composed of nano-sized domains [26]. Metallic cobalt and cobalt silicide in nanoparticle form are both active CNT catalysts [51]. Thus, it is not surprising that testing bare silicide samples without Fe catalyst leads to CNT growth under CVD conditions. The CNT yield is however significantly lower and only sparse, spaghetti-like CNTs grow (not shown). Nevertheless, this might suggest also a beneficial interplay between
Fe and Co catalysts [52-54], responsible for the excellent support properties of Co-silicides for CNT growth.

\subsection{Electrical data}

We now correlate the structural and chemical evolution of the Co-silicide samples with two-terminal I-V measurements. Figure 5(a) shows I-V curves corresponding to bare silicide samples (no Fe catalyst) as loaded, after pre-treatment and after exposure to atmospheric CVD conditions at $650^{\circ} \mathrm{C}$. As there was no $\mathrm{Fe}$ catalyst present, no CNT forest was grown and the small amount of CNTs grown from residual Co was stripped from the samples by adhesive tape. All films show a linear I-V relationship, implying that we form ohmic contacts with the probe tips. Hence, any oxide from transport in air is restricted to a $\sim 1$ $\mathrm{nm}$ thick layer, corroborating the characterisation results above. We find that the annealing and CVD step roughly halve the resistance in the silicide film. This is consistent with a transition from as-loaded, low conductivity $\mathrm{CoSi}$ films to a high conductivity $\mathrm{CoSi}_{2}$ phase in the annealed and CVD processed films, confirming our XRD assignments [30-32]. It also confirms our XRD result that no other high resistivity phases such as oxides or carbides are formed in the support during CVD.

We extended the I-V characterisation to include the CNTs by placing a copper TEM grid as a top electrode onto the forest surface, spreading the applied load from the probe tips over a large area to avoid squeezing/scratching off of CNTs. Gently contacting the grid with one probe tip leaves the forests intact, as checked by inspection of the forests after removal of the grid. The other probe tip was in direct contact to the Co-silicide film. Figure 5(b) shows that the resistance when contacting through the forest and the silicide compared to direct contact to the silicide increased only by a factor of two and developed only a slight nonlinearity. Considering the uncertainty in actual contact area on the forest, this shows that the CNTs do not significantly increase the overall system resistance.

The extraction of quantitative values from this data is complex, as several resistors in series contribute to it, most importantly the substrate-tube contact resistance, the internal tube resistance and the tube-(grid-)probe tip contact resistance (plus the resistances of the silicide film, the silicide-probe contact and the measurement setup). Furthermore, the macroscopic dimensions of probe station tips ( $\sim \mu \mathrm{m}$ radius) compared to the nanoscopic CNT diameters inhibit extraction of tube-specific values. Therefore, we refine our measurements by employing an IV-AFM setup using a conductive AFM tip ( $20 \mathrm{~nm}$ radius) as the top contact to the forest. The AFM feedback allows contacting of the CNTs with the application of a greatly reduced force compared to the macroscopic probe station tips, hence completely avoiding any squeezing, scratching off or damaging of the forest. We find linear, ohmic IV characteristics (Figure 5(c)) with measured resistances of $(80 \pm 60) \mathrm{k} \Omega$. With a tube density of $\sim 10^{10} \mathrm{CNTs} / \mathrm{cm}^{2}$ and the $\sim 20 \mathrm{~nm}$ 
(a)

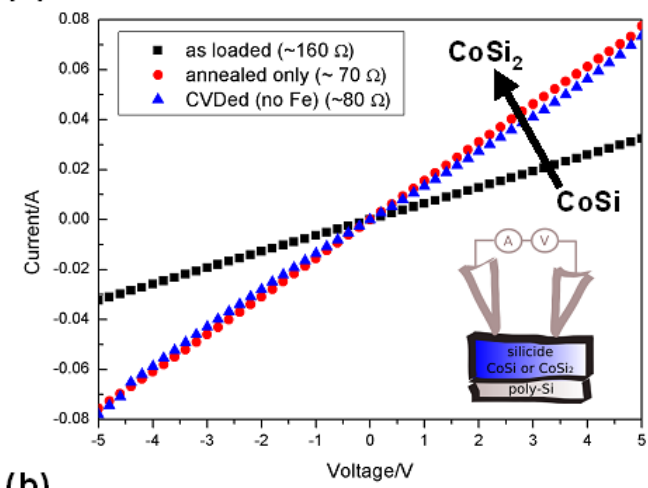

(b)

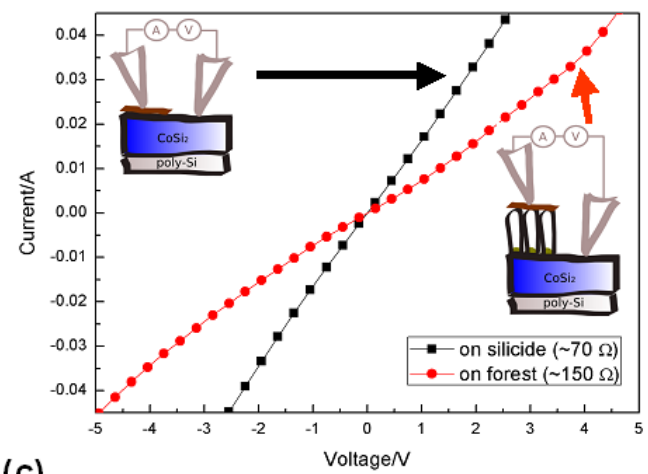

(c)

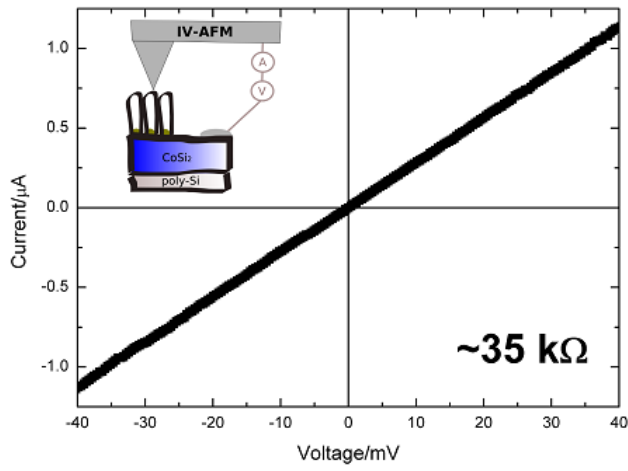

Figure 5: I-V characteristics of atmospheric pressure CVD samples: (a) Macroscopic probe station measurements of CVD processed samples from as loaded (black) and only pre-treated (red) to fully CVDed (blue) state. Note that as no Fe was on the samples the measurements do not include a contribution from CNTs. (b) Post-CVD probe station measurements comparing conduction through the silicide only (black) to conduction through the silicide and the CNT forest (red). (c) Post-CVD IV-AFM measurements through silicide and CNT forest (with only microscopic top contact area compared to (b)).

radius AFM tip, we estimate 1-10 tubes to be in contact with the AFM tip. This translates to a resistance per tube (incl. internal tube resistance and contact resistances to support and probe tip) on the order of a few tens to a few hundreds of $k \Omega$. Such values compare well to recent studies on CNT forest growth on conductive supports $[11,27]$ and confirm our probe station result that the CNTs are highly conductive.

Both low pressure and atmospheric pressure CVD give similar electrical results, indicating that despite the much higher residual gas contamination level in atmospheric pressure (especially residual oxygen and adsorbed water) cobalt silicide is a chemically very stable support compared to other potential support materials in microelectronics (e.g. compared to Ta [27]).

\section{Discussion}

We finally remark that any processing which involves exposure of the support-catalyst interface to ambient air conditions is detrimental to obtaining very low contact resistance. This is due to Co-silicides being susceptible to native oxidation similar to pristine Si. Also a too high residual oxygen or water partial pressure during annealing (or in our case CVD) can hinder full silicidation [30-32]. Therefore low pressure processes are preferable compared to atmospheric pressure furnace processes. Nevertheless, we found no significant differences in electrical properties from our low and atmospheric pressure CVD and hence conclude that the limiting contact influences in our samples come from other sources. In our low pressure CVD we saw that CNT growth proceeded partially on a freshly formed $\mathrm{CoSi}_{2}$ surface (from XPS), but most of the already existing thin $\mathrm{SiO}_{2}$ layer from sample transport in air was not removed in the CVD conditions. We attribute the main contact resistance to this layer, which was formed during sample exposure to air.

Hence, the following measures could further decrease the formation of any oxide barriers which limit the silicide-CNT contact performance: 1 . Cluster processing of support deposition/anneal, catalyst film deposition and CNT CVD without exposing samples to ambient at any stage. This would however be a cost intensive solution. 2 . Use of catalyst layer as capping layer: If the support is deposited \& annealed and the catalyst is deposited subsequently without breaking vacuum, a thick enough catalyst layer could prevent oxidation of the support surface when samples are then exposed to air. The catalyst is reduced by the pre-treatment gases during CVD and growth of CNTs on a pristine support surface may then be possible. However, this would require a rather thick, continuous catalyst layer, which is detrimental to the small catalyst particle sizes in high density, small diameter CNT growth. Specifically for our process flow and our obtained data, removing the remaining residual surface $\mathrm{Co}$ and the surface $\mathrm{SiO}_{2}$ by wet etches (where both etches need to be selective with respect to the silicide) before deposition of a sufficiently thick catalyst film could decrease any contact resistance from the thin $\mathrm{SiO}_{2}$. We are currently working towards optimisation of such etching processes.

Our data suggests that purely in terms of a catalyst support, $\mathrm{CoSi}_{2}$ is a preferable support, being of low resistivity and of low reactivity to bulk oxidation or carbide 
formation. NiPtSi is the preferred silicide in modern VLSI because it uses less Si than a disilicide [36] and hence NiP$\mathrm{tSi}$ is a further future CNT support candidate. TiN is the preferred contact metal below the 'metal-one' level in VLSI, because of its work function. We have previously analysed CNT growth on TiN [29]. However, TiN has the disadvantage that it is more easily oxidised while oxidative plasmas and similar treatments are valuable for increasing the CNT forest density and enforcing the relevant root growth $[55,56]$. Further work will need to deal with the application of such treatments also to $\mathrm{CoSi}_{2}$ supports in order to improve the CNT forest density.

\section{Conclusion}

We have characterised Fe catalysed CNT growth on conductive $\mathrm{CoSi}_{2}$ support in terms of structure and chemistry of the support and catalyst system. We employ in-situ silicidation to transform low conductivity $\mathrm{CoSi}$ to highly conductive $\mathrm{CoSi}_{2}$ during CNT forest CVD. We have con-

\section{References}

[1] B. Q. Wei, R. Vajtai, and P. M. Ajayan, Appl. Phys. Lett. 79, 1172 (2001).

[2] F. Kreupl, A. P. Graham, G. S. Duesberg, W. Steinhoegl, M. Liebau, E. Unger, and W. Hoenlein, Microelectron. Eng. 64, 399 (2002).

[3] J. Robertson, G. Zhong, S. Hofmann, B. C. Bayer, C. S. Esconjauregui, H. Telg, and C. Thomsen, Diamond Relat. Mater. 18, 957 (2009).

[4] M. Nihei, A. Kawabata, Y. Awano, Jpn. J. Appl. Phys. 42, L721 (2003).

[5] M. Nihei, M. Horibe, A. Kawabata, and Y. Awano, Jpn. J. Appl. Phys. 43, 1856 (2004).

[6] M. Nihei, A. Kawabata, D. Kondo, M. Horibe, S. Sato, and Y. Awano, Jpn. J. Appl. Phys. 441626 (2005).

[7] M. Katagiri, N. Sakuma, Y. Yamazaki, M. Suzuki, S. Sato, M. Nihei, T. Sakai, and Y. Awano, Jpn. J. Appl. Phys. 48 090205 (2009).

[8] Y. Yamazaki, M. Katagiri, N. Sakuma, M. Suzuki, T. Sakai, S. Sato, M. Nihei, and Y. Awano, Appl. Phys. Exp. 3, 055002 (2010).

[9] J. Dijon, A. Fournier, P. D. Szkutnik, H. Okuno, C. Jayet, and M. Fayolle, Diamond Relat. Mater. 19, 382 (2010).

[10] J. Dijon, H. Okuno, M. Fayolle, T. Vo, J. Pontcharra, D. Acquaviva, D. Bouvet, A. M. Ionescu, C. S. Esconjauregui, B. Capraro, E. Quesnel, and J. Robertson, Tech. Digest IEDM 2010, IEEE, 33.4.1 (2010)

[11] G. D. Nessim, M. Seita, K. P. O’Brien, A. J. Hart, R. K. Bonaparte, R. R. Mitchell, and C. V. Thompson, Nano Lett. 9, 3398 (2009)

[12] K. Hata, D. N. Futaba, K. Mizuno, T. Namai, M. Yumura, and S. Iijima, Science 306, 1362 (2004).

[13] Y. Murakami, S. Chiashi, Y. Miyauchi, M. Hu, M. Ogura, T. Okubo and S. Maruyama, Chem. Phys. Lett. 385, 298 (2004).

[14] G. Zhong, T. Iwasaki, K. Honda, Y. Furukawa, I. Ohdomari and H. Kawarada, Jpn. J. Appl. Phys. 441558 (2005). firmed that $\mathrm{CoSi}_{2}$ films are stable against (bulk) oxidation and carbide formation during CVD, and they provide an excellent conductive support material for vertically aligned $\mathrm{CNT}$ growth, resembling growth on the insulating $\mathrm{Fe} / \mathrm{Al}_{2} \mathrm{O}_{3}$ benchmark system. Our data implies that the excellent catalytic capabilities arise from an interfacial reaction of the $\mathrm{Fe}$ catalyst particles with the underlying $\mathrm{Co} / \mathrm{Si}$ in the support. We obtain ohmic conduction from the support layer to the CNT forest, where CVD conditions (silicidation) increase the conductivity of the stack.

\section{Acknowledgements}

We acknowledge funding from the EU Integrated Project "Technotubes" under grant agreement n. ${ }^{\circ} 26716$. We acknowledge the Helmholtz-Zentrum-Berlin BESSY II synchrotron and we thank the BESSY staff for continuous support.

[15] G. Zhong, T. Iwasaki, J. Robertson and H. Kawarada, J Phys. Chem. B 111, 1907 (2007).

[16] Y.-Q. Xu, E. Flor, M. J. Kim, B. Hamadani, H. Schmidt, R. E. Smalley, and R. H. Hauge, J. Am. Chem. Soc. 128, 6560 (2006)

[17] S. Noda, K. Hasegawa, H. Sugime, K. Kakehi, Z. Zhang, S. Maruyama and Y. Yamaguchi, Jpn. J. Appl. Phys. 46, L399 (2007).

[18] M. Cantoro, S. Hofmann, S. Pisana, V. Scardaci, A. Parvez, C. Ducati, A. C. Ferrari, A. M. Blackburn, K.-Y. Wang, and J. Robertson, Nano Lett. 6, 1107 (2006).

[19] C. Zhang, S. Pisana, C. T. Wirth, A. Parvez, C. Ducati, S. Hofmann, and J. Robertson, Diamond Relat. Mater. 17, 1447 (2008).

[20] C. T. Wirth, C. Zhang, G. Zhong, S. Hofmann, and J. Robertson, ACS Nano 3, 3560 (2009).

[21] T. Yamada, T. Namai, K. Hata, D. N. Futaba, K. Mizuno, J. Fan, M. Yudasaka, M. Yumura and S. Iijima, Nature Nanotech. 1, 131 (2006).

[22] T. de los Arcos, F. Vonau, M. G. Garnier, V. Thommen, H.G. Boyen, P. Oelhafen, M. Dueggelin, D. Mathis, and R. Guggenheim, Appl. Phys. Lett. 80, 2383 (2002).

[23] Y. Wang, B. Li, P. S. Ho, Z. Yao, and L. Shi, Appl. Phys. Lett. 89, 183113 (2006).

[24] Y. Wang, Z. Luo, B. Li, P. S. Ho, Z. Yao, L. Shi, E. N. Bryan, and R. J. Nemanich, J. Appl. Phys. 101, 124310 (2007).

[25] S. Esconjauregui, B. C. Bayer, M. Fouquet, C. T. Wirth, C. Ducati, S. Hofmann, and J. Robertson, Appl. Phys. Lett. 95, 173115 (2009).

[26] C. Zhang, F. Yan, C. S. Allen, B. C. Bayer, S. Hofmann, B. J. Hickey, D. Cott, G. Zhong, and J. Robertson, J. Appl. Phys. 108, 024311 (2010).

[27] B. C. Bayer, S. Hofmann, C. Castellarin-Cudia, R. Blume, C. Baehtz, S. Esconjauregui, C. T. Wirth, R. A. Oliver, C. 
Ducati, A. Knop-Gericke, R. Schlögl, A. Goldoni, C. Cepek, and J. Robertson, J. Phys. Chem. C 115, 4359 (2011).

[28] C. Jin, M. Delmas, P. Aubert, F. Alvarez, T. Minéa, M.C. Hugon, and B. Bouchet-Fabre, Thin Solid Films (2011), doi:10.1016/j.tsf.2011.01.367

[29] S. Esconjauregui, B. C. Bayer, M. Fouquet, C. T. Wirth, F. Yan, R. Xie, C. Ducati, C. Baehtz, C. Castellarin-Cudia, S. Bhardwaj, C. Cepek, S. Hofmann, and J. Robertson, submitted to J. Appl. Phys.

[30] K. Maex, Mat. Sci. Eng. R11, 53 (1993).

[31] E. G. Colgan, J. P. Gambino, and Q. Z. Hong, Mat. Sci. Eng. R16, 43 (1996).

[32] J. P. Gambino, and E. G. Colgan, Mater. Chem. Phys. 52, 99 (1998).

[33] K. Wetzig (ed.), and C. M. Schneider (ed.), Metal Based Thin Films for Electronics, $2^{\text {nd }}$ ed., Wiley-VCH Verlag, Weinheim, Germany (2006).

[34] S.-L. Zhang, and M. Oestling, Crit. Rev. Solid State Mater. Sci. 28, 1 (2003).

[35] C. Lavoie, F. M. d'Heurle, C. Detavernier, and C. Cabral, Microelectron. Eng. 70, 144 (2003).

[36] C. Lavoie, C. Detavernier, C. Cabral, F. M. d'Heurle, A. J. Kellock, J. Jordan-Sweet, and J. M. E. Harper, Microelectron. Eng. 832042 (2006).

[37] S. V. Meschel, and O. J. Kleppa,, J. Alloy. Compd. 321, 183 (2001).

[38] C. Mattevi; C. T. Wirth, S. Hofmann, R. Blume, M. Cantoro, C. Ducati, C. Cepek, A. Knop-Gericke, S. Milne, C. Castellarin-Cudia, S. Dolafi, A. Goldoni, R. Schloegl, and J. Robertson, J. Phys. Chem. C 112, 12207 (2008).

[39] S. Hofmann, R. Blume, C. T. Wirth, M. Cantoro, R. Sharma, C. Ducati, M. Haevecker, S. Zafeiratos, P. Schnoerch, A. Oesterreich, D. Teschner, M. Albrecht, A. Knop-Gericke, R. Schloegl, and J. Robertson, J. Phys. Chem. C 113, 1648 (2009).

[40] A. Knop-Gericke, E. Kleimenov, M. Hävecker, R. Blume, D. Teschner, S. Zafeiratos, R. Schlögl, V.I. Bukhtiyarov, V.V. Kaichev, I.P. Prosvinin, A. I. Nizovski, H. Bluhm, A. Barinov, P. Dudin, and M. Kiskinova, Adv. Catal. 52, 213 (2009).

[41] Note that in all CVD conditions the growth time (>20 $\mathrm{min}$ ) exceeds the constant growth rate regime and the forest height of tens of $\mu \mathrm{m}$ is due to self-termination of growth.

[42] PCPDFWIN, Version 2.4, 2003, JCPDS-ICDD, poly-Si: 271402, $\mathrm{CoSi}_{2}$ : 38-1449, CoSi: 50-1337, CoO: 89-2803, $\mathrm{Co}_{2} \mathrm{SiO}_{4}: 29-0506$.
[43] S.C. Petitto, E.M. Marsh, G.A. Carson, and M.A. Langell. J. Mol. Catal. A: Chem. 281, 49 (2008).

[44] G. Hollinger, Applications of Surface Science 8, 318 (1981).

[45] T. P. Nguyen, and S. Lefrant, J. Phys.: Condens. Matter 1, 5197 (1989).

[46] M. Aronniemi, J. Sainio, and J. Lahtinen, Surf. Sci. 578, 108 (2005)

[47] M. Descostes, F. Mercier, N. Thromat, C. Beaucaire, and M. Gautier-Soyer, Appl. Surf. Sci. 165, 288 (2000).

[48] R. Reiche, F. Yubero, J.P. Espinos, and A.R. Gonzalez-Elipe, Surf. Sci 457, 199 (2000).

[49] W. Platow, D. K. Wood, K. M. Tracy, J. E. Burnette, R. J. Nemanich, and D. E. Sayers, Phys. Rev. B 63, 115312 (2001).

[50] We note that with SEM and point localized energy dispersive $\mathrm{X}$-ray spectroscopy (EDX) we found that few large, $\mu \mathrm{m}$-sized Fe particles are present on parts of the sample surface. These particles are very likely not completely reduced during processing because of their size. While these are contaminations from sample preparation and inactive for growth, they might have artificially increased the non-reduced iron signal. Nevertheless the much larger sampled area of Co-silicide compared to the surface of the few Fe-particles indicates that the high Fe-oxide signal during processing is from a genuine interface effect. Furthermore, already without $\mathrm{C}_{2} \mathrm{H}_{2}$ exposure a small $\mathrm{FeC}$ component is visible in the $\mathrm{Fe} 2 \mathrm{p}$ when heating the samples. We attribute this to interactions with adventitious carbon from transport in ambient air [57].

[51] S. Esconjauregui, C. M. Whelan, and K. Maex, Nanotechnology 18, 015602 (2007).

[52] E. Flahaut, A. Govindaraj, A. Peigney, C. Laurent, A. Rousset, and C. N. R. Rao, Chem. Phys. Lett. 300, 236 (1999).

[53] W.-H. Chiang, and R. M. Sankaran, Nature Mater. 8, 882 (2009).

[54] W.-H. Chiang, and R M Sankaran, Adv. Mater. 20, 4857 (2008).

[55] S. Esconjauregui, M. Fouquet, B. C. Bayer, S. Eslava, S. Khachadorian, S. Hofmann, and J. Robertson, J. Appl. Phys. 109, 044303 (2011).

[56] S. Esconjauregui, M. Fouquet, B. C. Bayer, C. Ducati, R. Smajda, S. Hofmann, and J. Robertson, ACS Nano 4, 7431 (2010).

[57] N. Shabanova, and V. A. Trapeznikov, J. Electron Spectrosc. Relat. Phenom. 6, 297 (1975) 